\title{
La prefectura de los collegia profesionales y el cursus municipal en las ciudades de Pannonia
}

\author{
Henar Gallego Franco *
}

\begin{abstract}
RESUMEN ABSTRACT
El estudio de las fuentes epigráficas de las principales ciudades de Pannonia muestra una clara relación entre las aristocracias y magistrados municipales

$y$ el desempeño de los cargos directivos en los collegia profesionales.

El ejercicio de éstos en aquellas asociaciones de mayor prestigio, por su utilidad en la vida urbana,

especialmente los collegia fabrum y centonariorum, fue codiciado como un

A research through the epigraphical sources in the main cities of the roman province Pannonia evidences a strong link between the local aristocracies and magistrates and the direction of the professional associations. These directive posts in collegia of a great prestige based on their usefulness for the urban life, were very desirable as an important door for a social promotion.
\end{abstract} evidente trampolín de promoción social.

Aunque la abundante presencia de fuerzas militares en Pannonia ${ }^{1}$ marcó la forma de vida de sus habitantes, sus intereses y relaciones, lo

* Historia Antigua. Universidad de Valladolid.

1 Cir. A. Mócsy, Pannonia and Upper Moesia, London, 1974; A. DoBo, Die Venwaltung der römischen Provinz Pannonien von Augustus bis Diocletianus, Budapest, 1968; E. TorH, "Contribution a l'historique de la constitution de la provincia pannonia". Archaeologiai Ertesito, 2, 1976, 197-202; J. FITZ, La Pannonie sous Gallien. Bruselas, 1976; E. TOTH, "Comments on the development of Province Pannonia", Archaeologiai Ertesito, 108/1, 1981, 13-33; J. FITZ, L'administration des provinces pannoniennes sous le Bas Empire romain. Bruselas, 1983; J. FITZ, The great age of Pannonia (A.D. 193-284), Budapest, 1982; H. Gallego, Prosopografía, onomástica y sociedad en el Imperio Romano. Las provincias de Rhaetia, Noricum, Pannonia Superior e Inferior, Valladolid (microficha), 1996. 
que se reflejó en las estructuras sociales ${ }^{2}$, esta sociedad provincial ofrece aspectos más variados que los simplemente militares, haciéndose patente la existencia de una vida social civil urbana rica y variada en matices, de manera que el elemento militar, aunque importante, no es exclusivo en las estructuras sociales de Pannonia. En líneas generales, entre las provincias romanas del alto y medio Danubio, es Pannonia la que presenta unas estructuras sociales más desarrolladas, ricas y complejas, con una mayor variedad de situaciones. En relación a la vida municipal, destaca la mayor potencia de sus élites urbanas, que participan en el ámbito público y evergético de la provincia ${ }^{3}$.

En este contexto, los collegia profesionales ${ }^{4}$ aparecen como asociaciones intimamente relacionadas con la vida municipal en Pannonia, siendo significativo que muchos de sus puestos dirigentes, conocidos a través de las fuentes epigráficas, sean al mismo tiempo miembros de la aristocracia municipal. Tal es así, que los cargos directivos en estas asociaciones parecen ser de elección política, y su desempeño pasa a formar parte del cursus municipal que siguen los miembros de las aristocracias urbanas, en la que suponen un escalón más ${ }^{5}$.

2 Sobre el carácter de provincia fronteriza de Pannonia y la importancia cuantitativa de su guarnición militar, ctr. E.N. LuTTwaK, The Grand Strategy of the Roman Empire, London, 1976, 96-97 (mapa 2.5); J. FiTZ, "Les légions de la province an début du lle s.", Oikumene, 5, 1986, 329$369 ; \mathrm{K}$. Strobel, «La dislocation des légions romaines en Pannonie entre 89 et $118 \mathrm{pC}$, Tyche, 3 , 1988, 193-221; C.R. WhITTAKER, Frontiers of the Roman Empire. A social and Economic Study, London, 1994, 167-191; J. WACHER, The Roman Empire, London, 1987, 30, 59-61.

3 C.R. WHITTAKER, Frontiers of the Roman Empire. A Social and Economic Study, London, 1994, 98-131; S.K. DRUMmOND/J.H. NELSON, The Western Frontiers of Imperial Rome, New York, 1994, 60-68, 77-100, 101-108, 152-171; H. GALLEGO, Las Estructuras Sociales del Imperio Romano. Las provincias de Rhaetia, Noricum y Pannonia, Valladolid, 1997, 206-283 (en prensa).

* Sobre los collegia protesionales en el Imperio Romano: J.P. WALTZING, Étude historique sur les corporations professionnelles chez les Romains, Louvain, 1895-1900, 4 vol; Fr.M. DE RoBERTIS, Storia delle corporazioni e del regime associativo nel mondo romano, Bari, 1971, 2 vol; $L$. Gracco RugGiNI, "Le associazioni professionali nel mondo romano-bizantino", en Artigianato e tecnica nell società dell'alto medioevo occidentale (Settimane di studio del Centro italiano di studi sull'alto medioevo occidentale, xvIII), Spolète, 1971, 1, 59-193; G. CLEMENTE, «II patronato nei collegia dell'Impero romano", Studi classici e orientali, XXI, 1972, 142-229; L. Cracco RugGINI, "Stato e associazioni professionali nell'età imperiale romana", Akten des Internationalen Kongresses für Griechische und Lateinische Epigraphik (München, 1972), München, 1973, 271311.

5 Cir. R. Ardevan, “Le college des fabres a Ulpia Traiana Sarmizegetusa", Actes du VII Congres International d'epigraphie grecque et latine (Constantza, 9-15 septembre 1977). Paris, 1979, 327-328, detecta la existencia de praefecti en el collegium tabrum de la ciudad, elegidos entre los más altos magistrados de esta ciudad de Dacia; en Italia central y septentrional abundan, por otro lado, entre los patroni y praefecti de los collegia profesionales, los individuos con cargos municipales, cfr. M. SARTORI, “Un frammento di tabula patronatus del collegium centonariorum laudensium", Athenaeum, 65/I-II, 1987, 199; M. SARTORI, "ll collegium fabrum in un nuovo testo epigrafico patavino", Athenaeum, 55/III-IV, 1977, 410-411. 
En Pannonia Superior se atestigua este fenómeno entre las élites aristocráticas de importantes colonias y municipios. Uno de los núcleos principales de la provincia es la colonia Claudia Savaria (Szombathely, Hungría), sede del culto imperial y del concilium provincial ${ }^{6}$. Alli G. Iulius Maximus ${ }^{7}$, fue decurio coloniae, aedilicius y praefectus collegii fabrum centonariorum ${ }^{8}$. Además, la aristocracia de la colonia nos ofrece un cursus honorum de extraordinario interés, en el que se auna la carrera municipal con la vinculación a los collegia profesionales y una posterior carrera equestre. Se trata de la dilatada carrera pública de L. Octavius Faustinianus ${ }^{9}$.

Este hombre pertenece a una rama de los Octavii que florece en el sur de Pannonia en época severa, aunque el origen de la gens en la provincia es altoimperial. Su vinculación al culto de luppiter Optimus Maximus Depulsor puede indicar que su núcleo familiar procedía de otra colonia provincial, Poetovio, aunque el hecho de desarrollar la carrera municipal en Savaria puede indicar que él era originario de esta colonia Claudia. En efecto, Faustinianus desarrolla la carrera municipal completa en Savaria, donde es praefectus collegii fabrum et centonariorum, quaestoricius, aedilicius, Ilvir iure dicundo, IVvir quinquennalis, decurio y flamen ${ }^{10}$, pero también forma parte del ordo decurionum en Carnuntum ${ }^{11}$. Además se vincula con el collegium fabrum de Carnuntum (Petronell, Austria) ${ }^{12}$, la capital provincial, a través

6 Plinio, N.H., 3, 146; Ptolomeo, 2, 14, 4; Itin. Ant., 233, 5; 261, 7; 262, 6; 263, 3; 266, 4; Not. Dign. Occ., 5, 9; 7, 82; 11, 25. Cfr. J. FITZ, "Concilia provinciae in Pannonien", Festschrift $A$. Betz, 1985, 257-265.

AE 1965, 294, una votiva a Mercurius Augustus, probablemente de la segunda mitad del s. " o primer tercio del s. II d.C.; esta dedicación votiva, puede reflejar sus intereses en actividades comerciales, protegidas por esta divinidad; cfr. J.P. MARTiN, Les provinces romaines d'Europe centrale et occidentale. Société et Religions. Paris, 1991, 173-174; B. Combet-Farnoux, Mercure romain. Le culte public de Mercure et la fonction mercantile á l'epoque augustéenne. Roma, 1980.

\& AE 1965, 296 atestigua también la existencia del collegium fabrum et centonariorum de Savaria; ambos collegia aparecen unidos en varias ciudades de Pannonia, como Cibalis, cfr. CIL III 10253, o Aquincum, cfr. CIL III 3583, 3569; AE 1939, 8, escindiéndose en esta última es dos ramas distintas a partir del s. II d.C.; Este fenómeno de unión de los collegia de fabri y centonarii está bien constatado también en ltalia central y septentrional, cfr. Cfr. J.M. SALAMITO, "Les collèges de fabri, centonarii et dendrophori dans les villes de la regio $X$ à l'époque impériale", en VV.AA., La città nell'ltalia settentrionale in età romana (Atti del convegno organizzato dal Dipartimento di scienze dell'Antichità di Trieste e dall'École française de Rome, Trieste, 13-15 marzo 1987). Roma, 1990, 164, 166-167; F. SARTORI, "Il collegium fabrum in un nuovo testo epigrafico patavino", Athenaeum, 55/III-IV, 1977, 408

9 CIL III 4170; AE 1968, 422; I. TÓTH, «L. Octavius Faustinianus», Specimina Nova, 1986, 45; H. Devijver, Prosopographia Militiarum equestrium quae fuerunt ab Augusto ad Gallienum, Louvain, 1976/77-1987, 5bis Suppl.

10 I. Tотн, “L. Octavius Faustinianus", Specimina Nova, 1986, 45.

11 CIL III 4170.

12 Adquirió el rango de municipio con Hadriano y de colonia con Septimio Severo; cfr. Plinio, N.H., 4, 80; 33, 45; Ptolomeo, 2, 14, 3; Itin. Ant., 247, 2; 362, 3.8; 266, 14; 267, 12; Not. Dign. Occ., 34,26 y 28 . 
de la dedicación de una estatua del Genius ${ }^{13}$. Aunque la dirección del collegium fabrum suele ser un cargo político, sin duda su ejercicio responde también a una realidad socioeconómica, de manera que Faustinianus debía ser propietario de talleres y tierras en la zona de Poetovio, Carnuntum y Savaria, de manera que usaría su fortuna como trampolín para incorporarse a las élites dirigentes provinciales. Prueba de su fortuna son las liberalidades con las que obsequia a Savaria, donde levanta un porticus cum exedra ${ }^{14}$, consagrando la obra a luppiter Optimus Maximus Depulsor pro salute Savariensium, y a Carnuntum, donde pone la mencionada estatua del Genius ${ }^{15}$. Su fidelidad a la dinastía reinante fue premiada con el acceso al rango equestre ${ }^{16}$, iniciando a continuación una importante carrera militar ${ }^{17}$, y terminando su brillante ascensión social con el puesto de sacerdos Arae Augustorum provinciae Pannoniae Superioris ${ }^{18}$, que desarrollaría en Savaria, sede del concilium provincialis y del culto imperial ${ }^{19}$.

En el municipio flavio de Vindobona (Wien, Austria) ${ }^{20}$, G. Marcius Marcianus ${ }^{21}$ explicita su puesto de decurio municipii, junto con una dilatada carrera que incluye la jefatura del colegio de artesanos: quaestor, aedilis, IIvir iure dicundo y praefectus collegii fabrum. También en la colonia Septimia Siscia (Sisak, Croacia) ${ }^{22}$ contamos con el decurio G. Ingenuius Rufinianus ${ }^{23}$, que tiene en su haber el ejercicio de los cargos de quaestor rei publicae y praefectus collegii centonariorum.

Por otro lado, en la colonia lulia Emona (Ljubljana, Eslovenia) ${ }^{24}$ constatamos que esta vinculación entre el collegium fabrum y el ejercicio

13 AE 1968, 422, donde consagra una estatua al Genius en honor de este collegium y por la salud de Heliogábalo.

1. TOTH, «L. Octavius Faustinianus», Specimina Nova, 1986, 45.

AE 1968, 422

Equo publico en CIL III 4170.

AE 1966, 286=AE 1968, 422; AE 1983, 766. Cfr. I. TorH, "L. Octavius Faustinianus", Specimina Nova, 1986, 41-56, praefectus alae II Septimiae Surorum Hamiorum miliariae, tribunus cohortis II Mattiacorum miliariae equitatae, tribunus militum legionis XIII Geminae.

18 Conocemos un culto provincial al Ara Augusta a través del collegium del Genius Provinciae, cfr. CIL III 4168.

19 CIL III 4170; AE 1983, 766; H.G. KOLBE, "Die Laufbahn des Faustinianus aus carnuntum", Carnuntum Jahrbuch, VIII, 1963-1964, 48-54; G. ALFÖLDY, "Nochmals Octavius Faustinianus", Zeitschrift für Papyrologie und Epigraphik, 51, 1983, 230-236; Ist. TÖTH, «L. Octavius Faustinianus", Specimina Nova, 1986, 41-56.

20 Ptolomeo, 2, 14, 3; Itin. Ant., 233, 8; 248, 1; 261, 4; 266, 4; Not. Dign. Occ., 34, 25; 34, 28.

21 CIL III 4557, dedica una votiva a la Prosperitas Deorum, en el s. III d.C.

22 Estrabón, IV, 6, 10; VII, 5, 2; Plinio, N.H., 3, 147-148; Itin. Ant., 259, 11; 260, 2; 265, 5; 265, $11 ; 266,3 ; 272,9 ; 274,7$; Not. Dign. Occ., 11, 24; 32, 56-57; Zósimo,11, 45.

${ }_{23}$ CIL III 10836, datado en el s. III d.C., donde dedica a Hercules, junto con los suyos (cum suis).

${ }_{24}$ Plinio, N.H., 3, 128; 3, 147; Ptolomeo, 2, 14, 5; Itin. Ant., 129, 2; 259, 11; Ammiano Marcellino, XXVIII, 1, 45. 
de las magistraturas municipales puede producirse también a un nivel inferior, por ejemplo con el sevirato. Alli $L$. Caesernius Primitivus ${ }^{25}$, es sevir de la colonia y decurialis collegii, tratándose de un liberto acomodado relacionado con los Caesernii noritálicos del vecino municipio de Celeia (Celje, Eslovenia) ${ }^{26}$, en Noricum ${ }^{27}$. Un caso de características similares nos lo ofrece el municipio de Brigetio (Szöny, Hungría) ${ }^{28}$, donde Q. Ulpius Felix ${ }^{29}$ desempeña las funciones de augustalis municipii y praefectus collegii centonariorum.

Similares relaciones entre los collegia profesionales y las magistraturas municipales atestiguamos igualmente en los municipios y colonias de Pannonia Inferior, empezando por la capital, Aquincum (Budapest, Hungría) ${ }^{30}$, donde además de un cursus anónimo que menciona los cargos de decurio municipii, Ilvir iure dicundo y praefectus collegii fabrum ${ }^{31}$, conocemos la figura de Gl.? Pompeius Faustus ${ }^{32}$, decurio de la colonia, cuyo cursus honorum menciona los cargos de aedilis, Ilviralis y praefectus et patronus collegii fabrum; o de $C$. Iulius Viatorinus ${ }^{33}$, también decurio coloniae, y antes aedilicius y praefectus collegii centonariorum. En la colonia Aelia Mursa (Osijek, Croacia) ${ }^{34}$ el decurio T. Flavius Martinus ${ }^{35}$ desempeñó los puestos de praefectus collegii centonariorum y IIvir designatus.

25 CIL III 3893, s. II d.C., lega doscientos denarios a las cuatro decurias de artesanos para que lleven rosas a las Carnaria (fiestas de las diosas Carnae).

26 Plinio, N.H., 3, 146; Ptolomeo, 2, 13, 3; itin. Ant., 129, 4.

27 Cfr. M. HARDING/G. JACOBSEN, «Norditalische Zuwanderung nach Celeia während der ersten zwei Jahrhunderte n. chr.", Acta Archaeologica Academiae Scientiarum Hungaricae, XLI, 1989, 227-232.

${ }_{28}$ Ptolomeo, 2, 14, 3; Itin. Ant., 246, 2; 262, 9; 263, 2; 264, 7; 265, 3; Not. Dign. Occ., 33, 51; Orosio, VII, 32, 14.

29 CIL III 10972, 11042; AE 1944, 110; Destaca la importante actividad evergética llevada a cabo por este individuo en época Severa, que acompaña además de unas epula a favor del collegium centonariorum.

30 Al igual que Carnuntum, la capital de Pannonia Superior, Aquincum recibió el status de municipio bajo Hadriano y el de colonia con Septimio Severo, cfr. Ptolomeo, 2, 15, 4; Itin. Ant., 245; J. Wacher, The Roman Empire, London, 1987, 227-228.

31 AE 1937, 202, fragmento de votiva del s. II d.C..

32 CIL III 3438 votiva a luppiter Optimus Maximus; CIL III 10475, votiva del s. III d.C., no se conserva el nombre de la divinidad objeto de la dedicación.

${ }_{33} \mathrm{AE} 1934,118$, datada en el 228 d.C., el dedicante contribuye al embellecimiento de la sede del colegio: hydram collegio s(upra) s(cripto) de suo d(edit) d(edicavit).

${ }_{34}$ Recibió el status colonial con Hadriano, cfr. CIL III 3279; Ptolomeo, 2, 15, 4; 8, 7, 7; Itin. Ant., 131, 1; 232, 6; 243, 5; 265, 5; 267, 3; Eutropio, 9, 8, 1; 10, 12, 1; Not. Dign. Occ., 32, 52; Orosio, VII, 29, 12.

${ }_{35}$ A. \& J. SASEL, “Inscriptiones latinae quae in luguslavia inter annos MCMIl et MCMXL repertae et editae sunt", Situla, XXV, 1986, 3095, del s. II d.C., uno de sus libertos consagra este monumento votivo a luppiter Optimus Maximus por la salud de su patrono. 
De la documentación hasta aquí analizada se desprende que el puesto de praefectus collegii fabrum o de praefectus collegii centonariorum ${ }^{36}$, forma parte frecuentemente del cursus honorum de los decuriones de las colonias y municipios de Pannonia, independientemente de que posteriormente accedan o no al rango equestre. Este puesto, para el cual eran designados por un magistrado ${ }^{37}$, suele abrir el acceso a las magistraturas municipales o bien desempeñarse en las primeras etapas de la carrera municipal, aunque en otros casos es imposible determinar el escalón exacto de la misma en que fue desempeñado ${ }^{38}$. Incluso ciertos seviri y augustales, libertos enriquecidos, manifiestan también una clara vinculación con estos mismos collegia profesionales, simplemente como miembros o bien como directivos de la asociación ${ }^{39}$, sin duda con la intención de que esta relación les sirviera de puerta de entrada al cursus municipal superior.

Sin embargo, no sólo los collegia fabrum y centonariorum ofrecen nexos entre sus cargos directivos y las magistraturas municipales. Aunque en menor medida, otras asociaciones profesionales participan en el fenómeno. En este sentido apuntan algunos testimonios epigráficos de Pannonia Superior, dos de la colonia Iulia Emona, donde Iulius Fortunatus? ${ }^{40}$ expresa los cargos de IIIlvir y praefectus o magister del collegium naviculariorum, y $C$. Bassidius Secundus ${ }^{41}$ desarrolla un cursus que pasa por los cargos de aedilis iure dicundo bis, quaestor pecuniae publicae y llvir iure dicundo, junto con los de patronus collegii dendrophorum y praefectus et patronus collegii centonariorum. Otro procede de Brigetio, donde [--] Rufus ${ }^{42}$ desempeñó los cargos de augustalis y patronus del collegium opificium.

36 Los collegia de fabri, centonarii y dendrophori aparecen con frecuencia fundidos, bien dos de ellos o los tres, en ltalia central y septentrional. Son los tres collegia profesionales más importantes en la vida de la ciudad, ya que sus actividades, al margen de sus fines lucrativos, aseguraban un servicio público para el municipio en el campo de la construcción , carpintería y lucha contra los incendios. Cfr. J.M. SALAMITO, "Les collèges de fabri, centonarii et dendrophori dans les villes de la regio X à l'époque impériale", en VV.AA., La città nell'ltalia settentrionale in età romana (Atti del convegno organizzato dal Dipartimento di scienze dell'Antichità di Trieste e dall'École française de Rome, Trieste, 13-15 marzo 1987). Roma, 1990, 163-164; F. SARTORI, "ll collegium fabrum in un nuovo testo epigrafico patavino", Athenaeum, 55/III-IV, 1977, 408.

37 J.M. SALAMITO, "Les collèges de fabri, centonarii et dendrophori dans les villes...", 166.

38 Sobre esta problemática, cfr. J.M. SALAMITO, "Les collèges de fabri, centonarii et dendrophori dans les villes...", 169.

39 CIL III 3893, L. Caesernius Primitivus, sevir y decurialis collegii fabrum en Emona; AE44, 110, Q. Uipius Felix, augustalis y praefectus collegii centonariorum en Brigetio.

40 CIL III 10771, fragmento de funeraria fechable en los s. II-III d.C., donde no se conserva claramente el cargo que este individuo pudo ocupar en el collegium naviculariorum de la ciudad.

41 ClL III 10738, funeraria, probablemente de la primera mitad del s. II d.C.

42 AE 1944, 119, votiva deteriorada al Deus Silvanus, fechable entre mediados del s. II y s. III d.C. 
En conclusión, el desempeño de la prefectura de los collegia profesionales fue buscado con avidez entre las élites socioeconómicas de las ciudades pannonias, especialmente la de los collegia fabrum, centonariorum y dendrophorum, que gozaban de especial prestigio por su utilidad a la vida de la ciudad ${ }^{43}$. Como hombres de fortuna, en la mayor parte de los casos existiría además una coincidencia de intereses económicos entre sus negocios y los del collegium cuya prefectura desempeñaban. Sus apetencias se canalizaban de forma natural hacia aquellas asociaciones profesionales vinculadas especialmente con sus actividades económicas, como propietarios de talleres artesanales o actividades relacionadas con el transporte y el comercio ${ }^{44}$.

El resultado es el claro testimonio epigráfico de un grupo de individuos de las aristocracias urbanas, miembros del ordo decurionum en su mayoría, algunos de los cuales dan el salto al ordo equester ${ }^{45}$, que cuentan en su carrera pública con el ejercicio del cargo de praefectus en estos collegia profesionales. Excepcionalmente alguno de ellos auna el puesto de praefectus y el estatus honorífico de patronus del collegium ${ }^{46}$. Todos ellos están dotados de un excelente nivel económico, como evidencia su frecuente participación en liberalidades y actos de evergetismo que benefician a sus respectivos municipios y colonias ${ }^{47}$, así como el carácter prolífico de su comportamiento votivo ${ }^{48}$, o el status de patrono de libertos que

43 Cfr. este fenómeno, pero referido al patronato, para Italia, en J.M. SALAMITO, "Les collèges de fabri, centonarii et dendrophori dans les villes de la regio $X$ à l'époque impériale", en VV.AA., La città nell'italia settentrionale in età romana (Atti del convegno organizzato dal Dipartimento di scienze dell'Antichità di Trieste e dall'École française de Rome, Trieste, 13-15 marzo 1987). Roma, $1990,164$.

44 M. SARTOR!, "Un frammento di tabula patronatus del collegium centonariorum laudensium», Athenaeum, 65/1-1I, 1987, 199.

45 CIL III 4170; AE, 1968, 422, L. Octavius Faustinianus en Savaria.

46 CIL III 10738, C. Bassidius Secundus, patronus collegii dendrophorum y praefectus et patronus collegii centonariorum; CIL III 3438, GI.? Pompeius Faustus, praefectus et patronus collegii fabrum; El fenómeno del patronato es característico del siglo il y primera mitad del s. III d.C.. Los individuos que desempeñan este honor, son de alto rango social, capaces de beneficiar con liberalidades generosas a sus protegidos, y a menudo buscan mantener vivo este prestigio o su vinculación con un núcleo urbano concreto, cfr. M. SARTORI, "Un frammento di tabula patronatus...", 199; J.M. SALAMITO, "Les colleges de fabri, centonarii et dendrophori dans les villes...", 169-170.

47 Destacan por su calidad de evergetes L. Octavius Faustinianus, cfr. CIL IIl 4170; AE 1968, 422; I. Tӧтн, "L. Octavius Faustinianus", Specimina Nova, 1986, 45; L. Caesernius Primitivus, cfr. CIL III 3893; C. lulius Viatorinus, cfr. AE 1934, 118; Q. Ulpius Felix, cfr. CIL III 10973, 11042; AE 1944, 110.

48 AE 1965, 294, a Mercurius Augustus; I. TOTH, "L. Octavius Faustinianus", Specimina Nova, 1986, 45, a luppiter Optimus Maximus Depuisor, AE 1968, 422, al Genius; CIL III 4557, a Prosperitas Deorum; CIL III 10836, a Hercules; AE 1944, 119, al Deus Silvanus; Votivas que no han conservado el nombre de la divinidad: AE 1937, 202; CIL III 10475. 
ostenta alguno de ellos ${ }^{49}$. Cronológicamente, tal práctica se constata a través de nuestros testimonios en un período que comprende todo el s. II y el primer tercio del s. III d.C. Sin duda alguna esta estrecha vinculación entre la dirección de los collegia profesionales y el ordo decurionum y las magistraturas municipales contribuyó a reforzar la autonomía de las principales colonias y municipios de Pannonia Superior e Inferior frente al gobierno central, evidenciando una etapa de extraordinario vigor de la vida urbana y municipal provincial ${ }^{50}$.

49 A. \& J. SASEL, «Inscriptiones latinae quae in luguslavia inter annos MCMIl et MCMXL repertae et editae sunt", Situla, XXV, 1986, 3095.

5o J.M. SALAMITO, "Les colleges de fabri, centonarii et dendrophori dans les villes...", 169170, evidencia cómo la progresiva elección, como patronos de las asociaciones profesionales, de individuos con cargos en la administración central, contribuyó al debilitamiento de la autonomía local. 